\title{
Características físico-químicas e perfil de ácidos graxos de azeites obtidos de diferentes variedades de oliveiras introduzidas no Sul de Minas Gerais - Brasil
}

\section{Physicochemical characteristics and fatty acids profile of olive oils from different varieties of olive tree in southern Minas Gerais - Brazil}

\author{
Luiz Gustavo Vieira Cardoso ${ }^{1}$; Maria de Fátima Piccolo Barcelos ${ }^{2 *}$; \\ Adelson Francisco de Oliveira $^{3}$; Juciane de Abreu Ribeiro Pereira ${ }^{1}$; \\ Wilson César de Abreu4; Flávio de Araujo Pimentel ${ }^{4}$; \\ Maria das Graças Cardoso²; Michel Cardoso de Angelis Pereira²
}

\begin{abstract}
Resumo
Este trabalho teve por objetivo analisar, física e quimicamente, cinco variedades de oliveiras mantidas no banco de germoplasma pela EPAMIG, na Fazenda Experimental no município de Maria da Fé, MG. Foram avaliadas características físicas dos frutos e sementes (peso, diâmetro e comprimento) e algumas características químicas dos azeites extraídos de cinco variedades (índice de acidez, iodo, saponificação, peróxidos e perfil de ácidos graxos). A variedade Negroa apresentou percentual médio de lipideos $(28,2 \%)$ significativamente maior que as demais $(\mathrm{p}<0,05)$. Dentre as variedades estudadas a Negroa e JB1 apresentaram maior produtividade e valores de acidez, índice de saponificação, iodo e peróxidos mais compatíveis com as normas da ANVISA (2005) e o Codex Alimentarius (2003). Todas as variedades cultivadas em Maria da Fé apresentaram conteúdos de ácido oléico dentro do recomendado pelo Codex alimentarius e significativamente maior que o teor de ácido oléico do azeite comercial extra virgem analisado $(\mathrm{p}<0,05)$. O perfil de ácidos graxos encontrado demonstrou que todas as variedades (JB1, Negroa, Ascolano 315, 0025 e 0004) estão com seus valores adequados para os principais grupos de ácidos graxos, quando comparados com a legislação. Os resultados indicam que das variedades analisadas a Negroa e JB1 apresentam melhor potencial para utilização na produção de azeite de oliva. Palavras-chave: Azeite de oliva, oliveira, ácidos graxos
\end{abstract}

\footnotetext{
Abstract

This work had as an objective, to analyze, both physically and chemically, five olive tree varieties kept in the EPAMIG Germplasm Bank at the Experimental Farm, in the town of Maria da Fé, MG. Physical characteristics of the fruits and seeds (weight, diameter and length) and some chemical characteritics of the oils extracted from five varieties (acidity, iodine, saponification, peroxide indices and the fatty acid profile) were evaluated. The Negroa variety presented an average percent of lipids (28.2\%) significantly higher than the others $(p<0.05)$. Out of the studied varieties, both Negroa and JB1 showed the highest

1 Mestre em Ciência dos Alimentos. DCA/UFLA. Caixa Postal 3037, Lavras/MG E-mail: luizgvc11@gmail.com

2 Professores da UFLA. Campus Universitário, CEP: 37200-000, Caixa Postal 3037. Lavra/MG E-mail: piccolob@ufla.br

3 Pesquisador da Empresa de Pesquisa Agropecuária de Minas Gerais (EPAMIG). Caixa Postal 3037, Lavras/MG E-mail: ctsm@

4 Doutorando em Ciência dos Alimentos. DCA/UFLA. Caixa Postal 3037, Lavras/MG, E-mail: wilsonprofessor@oi.com.br epamig.ufla.br

* Autor para correspondência 
yield and acidity values and the saponification, iodine and peroxide indices were more consistent with the ANVISA norms (2005) and the Codex Alimentarius (2003). All the varieties grown at Maria da Fé presented oleic acid levels within those recommended by Codex alimentarius and significantly higher than the analyzed commercial extra virgin oleic acid level $(\mathrm{p}<0.05)$. The fatty acid profile found showed that all the varieties (JB1, Negroa, Ascolano 315, 0025 and 0004) have adequate values for the main groups of fatty acids, compared with the legislation. The results point out that the Negroa and JB1 varieties present better potential for use in olive oil production.

Key words: Olive oil, olive tree, fatty acids, oleic acids

\section{Introdução}

O azeite de oliva é o principal produto obtido dos frutos da oliveira (Olea europaea Linné). Por suas características organolépticas é muito apreciado sendo largamente utilizado na dieta dos países situados na região do mar Mediterrâneo (PEIXOTO; SANTANA; ABRANTES, 1998).

Nos últimos anos, o cultivo de oliveiras adquiriu especial relevância em todo o mundo pelas propriedades benéficas do azeite de oliva à saúde humana (OLIVEIRA, 2001a). Por exemplo, um dos fatores associados à baixa mortalidade por doenças cardiovasculares observada nas populações da região mediterrânea é a elevada ingestão de ácido oléico presente no azeite de oliva (VOGNILD et al., 1998).

As características físico-químicas do azeite de oliva variam de acordo com o tipo de solo, clima, práticas culturais, variedades, estado de maturação do fruto e com as técnicas de extração. É importante enfatizar que o azeite de oliva, para ser comercializado, precisa apresentar-se dentro dos padrões da legislação vigente, com base em análises físico-químicas que o qualificarão dentro de determinadas classes específicas (AUEDPIMENTEL et al., 2002; MATIAS; LASTA, 2001).

No contexto mundial, o Brasil se posiciona entre os maiores importadores de azeite de oliva, não possuindo uma produção agrícola para atender ao mercado interno. Entre 1996 e 1998 houve um aumento de 44\% nas importações, sendo a Argentina, Espanha e Portugal os principais fornecedores (AUED-PIMENTEL et al., 2002; PIO et al., 2005).
Embora o Brasil seja um país tropical, possui, pela grande extensão territorial, regiões com condições climáticas e características adequadas para o cultivo de oliveiras e para a industrialização de seus produtos (PIO et al., 2005; SANTOS, 2005). O planalto de Poços de Caldas e a região da Alta Mantiqueira, que inclui Maria da Fé, no extremo Sul de Minas Gerais, vem realizando nos últimos anos o cultivo de algumas variedades de oliveira, pois apresentam condições edafoclimáticas favoráveis para o cultivo de espécies de clima temperado como as oliveiras (OLIVEIRA; ANTUNES; SCHUCH, 2006).

Diante do exposto, este trabalho teve por objetivos analisar as características físico-químicas e o perfil de ácidos graxos dos azeites de oliva extraídos de variedades de oliveira conservadas em bancos de germoplasma, pela Empresa de Pesquisa Agropecuária de Minas Gerais (EPAMIG) em sua Fazenda Experimental, no município de Maria da Fé, MG.

\section{Material e métodos}

O trabalho foi realizado no Departamento de Ciência dos Alimentos (DCA) da Universidade Federal de Lavras (UFLA), em Lavras, MG. As amostras de azeitonas foram cedidas pela Empresa de Pesquisa Agropecuária de Minas Gerais (EPAMIG). Foram colhidas $10 \mathrm{~kg}$ de azeitonas de cinco variedades (JB1, Ascolano 315, Negroa, 0025 e 0004) na Fazenda Experimental da EPAMIG, no município de Maria da Fé, MG, no mês de fevereiro de 2005, caracterizando o final da safra. 
Análises fisicas dos frutos

Os frutos de cada variedade de oliveira $(0025$, 0004, JB1, Ascolano 315 e Negroa) foram pesados, obtendo-se o peso médio de cem frutos frescos por meio de quatro pesagens. Os diâmetros e comprimentos dos frutos frescos, foram medidos (mm) utilizando um paquímetro, em dez repetições de cada variedade, conforme Barcelos (1998).

\section{Análises químicas}

A determinação do extrato etéreo das azeitonas foi realizada na amostra seca, pelo método de "Soxhlet", conforme Association of Official Analytical Chemists - AOAC (1990).

\section{Extração de lipídios das olivas}

Para a obtenção do azeite triturou-se todo o fruto (polpa e caroço) e a extração foi realizada conforme a metodologia de Folch, Lass e Stanley (1957), adaptada para amostras de $5 \mathrm{~g}$, que foram homogeneizadas em $50 \mathrm{~mL}$ de clorofórmio/metanol (2:1). A amostra homogeneizada foi filtrada em funil de separação de $250 \mathrm{~mL}$, permanecendo em repouso por 2 horas para separação física. A fração orgânica do homogeneizado, contendo lipídios e clorofórmio, foi recolhida e a fração aquosa foi descartada.

\section{Análises químicas no azeite de oliva}

\section{Determinação da acidez em ácido oléico}

A determinação da acidez foi realizada por titulação com solução de éter etílico e álcool e indicador fenolftaleína, de acordo com a técnica do Instituto Adolfo Lutz segundo Walkyria et al. (1976) e AOAC (1990) e o resultado foi expresso em \% de ácido oléico $(\mathrm{m} / \mathrm{m})$.
Determinação do índice da saponificação do azeite de oliva

O índice da saponificação foi determinado por titulação de hidróxido de potássio $4 \%$ e ácido clorídrico, de acordo com a técnica do Instituto Adolfo Lutz segundo Walkyria et al. (1976) e AOAC (1990).

\section{Determinação do índice de iodo}

$\mathrm{O}$ índice de iodo dos azeites foram determinados seguindo-se a técnica descrita pelas normas do Instituto Adolfo Lutz segundo Walkyria et al. (1976) e AOAC (1990), utilizando titulação com a solução de Wijs, em que a quantidade, em mg, de iodo absorvido por $100 \mathrm{~g}$ de óleo foi obtida pela diferença entre os volumes gastos na titulação do branco e da amostra.

\section{Determinação do índice de peróxidos}

$\mathrm{O}$ índice de peróxidos foi determinado, segundo a AOAC (1990), pela capacidade da amostra em oxidar iodeto de potássio, e os resultados foram expressos em miliequivalentes.

Determinação do perfil de ácidos graxos dos azeites de oliva

A extração do azeite foi realizada conforme a metodologia descrita por Folch, Lass e Stanley (1957). Em seguida 5mL de azeite de cada variedade e de uma marca comercial foram esterificados segundo metodologia de Hartman e Lago (1973). A determinação da composição de ácidos graxos foi realizada por cromatografia de fase gasosa utilizandose cromatógrafo marca Shimadzu modelo CG-17 ${ }^{\mathrm{a}}$, equipado com detector de ionização de chama, injetor split na razão 1:20, coluna capilar OV-fused sílica fundida, comprimento $30 \mathrm{~m}$ x $0,25 \mathrm{~nm}$. 
As condições cromatográficas utilizadas foram: temperatura inicial da coluna igual a $40^{\circ} \mathrm{C}$ por 5 minutos, aumentada a uma taxa de $10^{\circ} \mathrm{C} /$ minuto até a temperatura de $140^{\circ} \mathrm{C}$, permancendo 15 minutos, até temperatura final da coluna de $240^{\circ} \mathrm{C}$ com aquecimento de $4^{\circ} \mathrm{C} /$ minuto, permanecendo por 30 minutos. $\mathrm{O}$ gás de arraste utilizado foi o nitrogênio ultrapuro com um fluxo de $1 \mathrm{~mL} /$ minuto. A temperatura do injetor e detector foi de $260^{\circ} \mathrm{C}$. A identificação dos diferentes ácidos graxos foi realizada por comparação entre os tempos de retenção das amostras e dos padrões.

\section{Delineamento experimental e análise estatística}

O delineamento experimental utilizado foi o inteiramente casualizado com 5 tratamentos (variedades de oliveiras) e 4 repetições. Os dados foram submetidos a análise de variância complementada pelo teste de Tukey para comparações múltiplas. O nível de significância adotado foi igual ou menor a $5 \%$.

\section{Resultados e discussão}

Análises físicas e químicas dos frutos

Os valores médios e o erro padrão da média das análises das características físicas das variedades de oliveiras encontram-se na (Tabela 1). A variedade que apresentou maiores perímetros (fruto e semente) e peso em 100/unidades do fruto foi a Negroa. Por outro lado, a variedade 0025 foi a que apresentou menores valores de seus perímetros (fruto e semente) e peso em relação às demais.

Segundo Rapoport (1998), o fruto pode variar suas dimensões em função da variedade, podendo apresentar entre 10 a $40 \mathrm{~mm}$ de comprimento e diâmetro de 6 a $20 \mathrm{~mm}$, ressaltando-se, então, que a média geral para as dimensões dos frutos das variedades estudadas apresentou valores abaixo do encontrado em países produtores.

Pode-se observar que as diferenças apresentadas em relação ao peso de 100 frutos frescos foram inferiores quando comparadas à de países olivícolas, que chegam à média de $1.000 \mathrm{~g}$ por 100 frutos. Há uma relação inversa entre o tamanho do fruto e o rendimento em azeite de oliva. Em geral, frutas grandes apresentam baixo rendimento em azeite, por isso, são recomendadas para conservas e consumo em mesa. Por outro lado, frutos pequenos apresentam maior rendimento em azeite sendo destinados a indústria de extração de azeite. Segundo Oliveira (2001b), o tamanho do fruto é uma das principais características observadas e, em função disso, os frutos maiores são utilizados verdes para "conservas".

É importante ressaltar que estes parâmetros, além de variarem em função da variedade considerada, são também altamente influenciados pelo clima da região de plantio, podendo ainda variar de um determinado local para o outro.

Tabela 1. Média e erro padrão das características físicas das azeitonas de cinco variedades coletadas na Fazenda Experimental da EPAMIG na cidade de Maria da Fé, Minas Gerais.

\begin{tabular}{cccccc}
\hline \multirow{2}{*}{ Variedades } & Peso de 100 frutos & \multicolumn{2}{c}{ Frutos } & \multicolumn{2}{c}{ Sementes } \\
\cline { 3 - 6 } & $(\mathrm{g})$ & Comprimento & Diâmetro & Comprimento & Diâmetro \\
\hline Negroa & $373,57 \pm 27,86^{\mathrm{a}}$ & $19,56 \pm 1,17^{\mathrm{a}}$ & $14,69 \pm 0,91^{\mathrm{a}}$ & $14,27 \pm 0,36^{\mathrm{a}}$ & $6,57 \pm 0,22^{\mathrm{a}}$ \\
JB1 & $269,92 \pm 32,17^{\mathrm{b}}$ & $18,94 \pm 1,59^{\mathrm{a}}$ & $13,95 \pm 1,32^{\mathrm{a}}$ & $13,16 \pm 0,44^{\mathrm{a}}$ & $5,99 \pm 0,18^{\mathrm{a}}$ \\
0004 & $231,24 \pm 12,64^{\mathrm{b}}$ & $17,55 \pm 1,25^{\mathrm{a}}$ & $13,42 \pm 0,95^{\mathrm{a}}$ & $12,65 \pm 0,23^{\mathrm{b}}$ & $6,51 \pm 0,12^{\mathrm{a}}$ \\
Ascolano 315 & $183,62 \pm 16,92^{\mathrm{c}}$ & $18,06 \pm 2,32^{\mathrm{a}}$ & $12,81 \pm 1,13^{\mathrm{b}}$ & $12,92 \pm 0,39^{\mathrm{b}}$ & $6,88 \pm 0,15^{\mathrm{a}}$ \\
0025 & $108,99 \pm 6,35^{\mathrm{d}}$ & $13,24 \pm 0,83^{\mathrm{c}}$ & $9,46 \pm 0,42^{\mathrm{b}}$ & $10,8 \pm 0,33^{\mathrm{c}}$ & $5,59 \pm 0,15^{\mathrm{b}}$ \\
\hline
\end{tabular}

Médias seguidas da mesma letra, na coluna, são iguais entre si, pelo teste de Tukey, ao nível de 5\% de significância. Médias obtidas da pesagem de 100 frutos com 4 repetições. 
Os frutos das cinco variedades estudadas apresentaram elevados teores percentuais de lipídeos: Negroa (28,2\%), 0025 (25,6\%), JB1 (25,6\%), 0004 (21,6\%) e Ascolano 315 (20,0\%), semelhantes a diversas variedades cultivadas na Espanha (GUILLÉN; LÓPEZ-VILLATA, 1992). Segundo Robbers, Speedie e Tyler (1997) o conteúdo de lipídios comumente encontrado em frutos entre espécies varia de $20 \%$ a $30 \%$.

\section{Análises químicas no azeite de oliva}

A (Tabela 2) apresenta valores médios do índices de acidez, de saponificação, de iodo e de peróxido para verificação de sua pureza e os respectivos erros padrão da média.

Os valores de acidez dos azeites de oliva estudados variaram, conforme (Tabela 2), entre $2,20 \%$ (variedade JB1) e 3,62\% (variedade 0004) $(p<0,05)$. Estes valores elevados de acidez podem ser decorrentes da extração realizada com solventes, grau de maturação dos frutos e o tempo decorrido entre a colheita dos frutos e a extração do azeite que não deve ultrapassar 4 horas.

Os valores de acidez da (Tabela 2) encontram-se acima do valor máximo preconizado pela legislação brasileira (ANVISA, 2005), os quais variam de 0,3g/100g em ácido oléico (para azeite de oliva refinado) a 2,0g/100g em ácido oléico (para azeite de oliva virgem). Os valores médios encontrados neste trabalho estão acima dos relatados por Peixoto, Santana e Abrantes (1998), que analisaram dez marcas de azeite de oliva coletadas no mercado do Rio de Janeiro, no ano de 1995 e encontraram valores de acidez entre $0,15 \%$ e $0,85 \%$. Os referidos autores informam que o índice de acidez está relacionado à qualidade do azeite de oliva e pode ser influenciado por fatores como maturação, estocagem, ação enzimática, qualidade da azeitona e sistema de obtenção do azeite (extração mecânica e ou por solvente), pelo grau de refinação ou se apresentam puros ou se tratam de misturas.

Tabela 2. Valores médios e respectivos erros padrão dos índice acidez em acido oléico, índice de saponificação, índice de iodo e índice de peróxidos nas amostras de azeites de oliva .

\begin{tabular}{ccccc}
\hline Variedades & $\begin{array}{c}\text { Acidez em ácido } \\
\text { oléico (\%) }\end{array}$ & $\begin{array}{c}\text { Índice de } \\
\text { saponificação }(\mathrm{mg})\end{array}$ & $\begin{array}{c}\text { Índice de iodo } \\
\left(\mathrm{gl}^{2} / 100 \mathrm{~g}\right)\end{array}$ & $\begin{array}{c}\text { Índice de peróxido } \\
\left(\mathrm{meq} \mathrm{kg}^{-2}\right)\end{array}$ \\
\hline Negroa & $2,39 \pm 0,18^{\mathrm{bc}}$ & $170,03 \pm 30,94^{\mathrm{ab}}$ & $75,30 \pm 4,60^{\mathrm{a}}$ & $13,30 \pm 2,67^{\mathrm{a}}$ \\
JB1 & $2,20 \pm 0,08^{\mathrm{c}}$ & $189,10 \pm 15,30^{\mathrm{ab}}$ & $82,02 \pm 4,70^{\mathrm{a}}$ & $13,90 \pm 2,40^{\mathrm{a}}$ \\
0004 & $3,62 \pm 0,10^{\mathrm{a}}$ & $115,72 \pm 35,40^{\mathrm{b}}$ & $85,73 \pm 5,50^{\mathrm{a}}$ & $18,40 \pm 2,33^{\mathrm{a}}$ \\
Ascolano 315 & $3,47 \pm 0,32^{\mathrm{ab}}$ & $100,80 \pm 57,30^{\mathrm{b}}$ & $84,80 \pm 4,47^{\mathrm{a}}$ & $11,15 \pm 0,61^{\mathrm{a}}$ \\
0025 & $2,74 \pm 0,35^{\mathrm{ab}}$ & $310,10 \pm 13,30^{\mathrm{a}}$ & $51,80 \pm 6,00^{\mathrm{b}}$ & $25,50 \pm 6,10^{\mathrm{a}}$ \\
\hline
\end{tabular}

Médias seguidas da mesma letra, na coluna, são iguais entre si, pelo teste de Tukey ao nível de 5\% de significância. Médias obtidas de 4 repetições para cada variedade.

NotrabalhodePérez-Camino, GarciaeCastelliano (1992), os fatores que influenciaram a acidez foram maturação, manejo pós-colheita das azeitonas, ação enzimática, qualidade da oliva, pragas e doenças, presença de danos físicos ou fermentação, além do sistema de obtenção do azeite (mecânica/ solvente). Com isso, segundo Oliveira (2001b), o aumento da acidez ocorre quando há uma combinação de algumas variáveis, tais como temperatura, presença de sabões no óleo e umidade.

Quanto ao índice de saponificação dos azeites de oliva observou-se, conforme (Tabela 2), variação de 100,80mg (Ascolano 315) a 310,10mg (0025). Nota-se que a única variedade a se apresentar dentro dos padrões de referência para os índices de saponificação recomendados pelo Codex 
Alimentarius (2003) foi a variedade JB1 (189,1mg), sendo que os padrões de referência variam de 182 a $196 \mathrm{mg}$, independente do tipo de azeite. Os índices de saponificação das variedades Ascolano 315, 0004 e Negroa apresentaram-se abaixo do padrão legal e a variedade 0025 foi a única que apresentou valor superior aos padrões de referência. Segundo Gomes et al. (2003), o índice de saponificação é uma medida do tamanho da cadeia dos ácidos graxos que compõem o material lipídico. Quanto menor o peso molecular do ácido graxo, tanto maior será o índice de saponificação (WALKYRIA et al., 1976).

Trabalhos realizados por Gomes et al. (2003), mostraram que o índice de saponificação do óleo de soja mostrou-se abaixo do preconizado pelas normas legais. Portanto, alguns fatores, como a utilização de solvente para a extração, podem estar influenciando essa medida.

Quanto ao índice de iodo dos azeites de oliva observou-se, conforme (Tabela 2), que entre as variedades estudadas a variedade de oliveira 0025 apresentou índice de iodo do azeite significativamente menor que as demais. $\mathrm{O}$ azeite extraído das variedades Negroa, JB1, 0004 e Ascolano 315 apresentaram índice de iodo dentro das recomendações da ANVISA no 482/MS (1999) (75 a $90 \mathrm{gI}^{2} / 100 \mathrm{~g}$ ) e do Codex Alimentarius (2003), que estipula o índice de iodo de 75 a $94 \mathrm{gI}^{2} / 100 \mathrm{~g}$.

O índice de iodo é uma medida do grau de insaturação dos ácidos graxos presentes na gordura. Segundo o Codex Alimentarius (1993), o índice de iodo cria possibilidades de identificação de adulterações grosseiras em diversos tipos de óleos, tornando-os facilmente detectáveis. Isso porque ele mede o grau de insaturação dos ácidos graxos presentes no material lipídico analisado.

Peixoto, Santana e Abrantes (1998), analisando dez marcas de azeite de oliva (cinco importadas acondicionadas no Brasil e cinco importadas acondicionadas no país de origem) comercializadas no Rio de Janeiro, verificaram valores do índice de iodo variando entre 76,43 a 127,46 $\mathrm{gI}^{2} / 100 \mathrm{~g}$ das cinco marcas acondicionadas no Brasil. Duas amostras nacionais avaliadas apresentaram índice de iodo acima dos padrões do Codex Alimentarius (2003).

Quanto ao índice de peróxido, observou-se conforme (Tabela 2), que entre as variedades de oliveiras estudadas, apenas a 0025 apresentou índice de peróxidos do azeite de oliva acima do valor de referência para o consumo humano, o qual é da ordem 20 meq. de $\mathrm{O}_{2}$ ativo/kg (BENEDICO; PÉREZ; MARTINEZ, 2002; MORETTO; FETT, 1998). Provavelmente, durante a extração do azeite da referida variedade possa ter ocorrido oxidações indesejáveis nos seus antioxidantes naturais, ou ainda o índice de peróxido pode ter sido afetado pelas condicionantes pós-colheitas ocorridas no presente estudo.

O índice de peróxidos determina a oxidação inicial, a rancificação do azeite de oliva e a deterioração que pode ter havido nos antioxidantes naturais, como os tocoferóis e os polifenóis. Kobori e Jorge (2005) observaram valores elevados fora dos padrões de referência para índice de peróxidos em óleo de semente laranja, ocorrido devido ao processo de extração por solvente, que a partir do resíduo seco em estufa, pode ter provocado uma oxidação durante a secagem.

Segundo o Codex Alimentarius (2003) e RDC 270 da ANVISA (2005), o índice de peróxidos dever ser no máximo, $20 \mathrm{meq} / \mathrm{kg}$ para o azeite de oliva virgem, $15 \mathrm{meq} / \mathrm{kg}$ para o azeite de oliva e $5 \mathrm{meq} / \mathrm{kg}$ para o azeite de oliva refinado. Porém, Monferrer e Villalta (1993) mencionaram que índice de peróxidos para óleos em geral não pode atingir valores acima de $15 \mathrm{meq} / \mathrm{kg}$, considerado, assim, como indicativo para o descarte do óleo.

\section{Perfil de ácidos graxos do azeite de oliva}

A (Tabela 3) apresenta o perfil de ácidos graxos dos azeites de olivas extraídos de cinco variedades de oliveiras e do azeite de oliva extra virgem comercial. 
Tabela 3. Valores médio (\%) e erro padrão do perfil de ácidos graxos do azeite de oliva dos frutos de cinco variedades de oliveira e de um azeite extra virgem comercial.

\begin{tabular}{|c|c|c|c|c|c|c|c|}
\hline \multirow{2}{*}{ Ácido graxo } & \multicolumn{5}{|c|}{ Teor de ácidos graxos (\%) das variedades de oliveiras } & \multirow{2}{*}{$\begin{array}{c}\text { Azeite } \\
\text { comercial }\end{array}$} & \multirow{2}{*}{$\begin{array}{c}\text { Codex } \\
\text { Alimentarius } \\
(2003)\end{array}$} \\
\hline & JB1 & Ascolano315 & 0025 & 0004 & Negroa & & \\
\hline $16: 0$ & $13,71 \pm 0,16^{\mathrm{a}}$ & $13,36 \pm 0,17^{\mathrm{ab}}$ & $5,52 \pm 0,17^{\mathrm{c}}$ & $10,91 \pm 0,28^{\mathrm{c}}$ & $13,07 \pm 0,09^{\mathrm{ab}}$ & $12,36 \pm 0,47^{b}$ & $7,5-20,0$ \\
\hline $16: 1$ & $2,77 \pm 0,09^{\mathrm{a}}$ & $0,82 \pm 0,02^{\mathrm{d}}$ & $0,36 \pm 0,04^{\mathrm{e}}$ & $1,52 \pm 0,04^{\mathrm{c}}$ & $2,42 \pm 0,03^{\mathrm{b}}$ & $1,33 \pm 0,03^{\mathrm{c}}$ & $0,3-3,5$ \\
\hline Margárico & $0,19 \pm 0,01^{\mathrm{a}}$ & $\operatorname{tr}$ & $\operatorname{Tr}$ & $0,23 \pm 0,02^{\mathrm{a}}$ & $0,19 \pm 0,02^{\mathrm{a}}$ & $\operatorname{tr}$ & $0,0-0,3$ \\
\hline Esteárico & $1,23 \pm 0,03^{\mathrm{d}}$ & $2,29 \pm 0,01^{\mathrm{a}}$ & $1,67 \pm 0,07^{\mathrm{c}}$ & $1,36 \pm 0,07^{\mathrm{d}}$ & $1,33 \pm 0,01^{\mathrm{d}}$ & $1,92 \pm 0,04^{\mathrm{b}}$ & $0,5-5,0$ \\
\hline Oléico & $68,76 \pm 0,57^{\mathrm{bc}}$ & $65,54 \pm 0,37^{\mathrm{c}}$ & $78,49 \pm 1,26^{\mathrm{a}}$ & $67,38 \pm 1,23^{c}$ & $72,55 \pm 0,22^{\mathrm{b}}$ & $58,56 \pm 0,51^{\mathrm{d}}$ & $55,0-83,0$ \\
\hline Elaidico & $3,81 \pm 0,05^{\mathrm{d}}$ & $9,77 \pm 0,02^{\mathrm{b}}$ & $2,67 \pm 0,07^{\mathrm{e}}$ & $6,04 \pm 0,12^{\mathrm{c}}$ & $3,93 \pm 0,04^{\mathrm{c}}$ & $12,11 \pm 0,24^{\mathrm{a}}$ & $0,0-0,05$ \\
\hline Linoléico & $0,54 \pm 0,02^{\mathrm{c}}$ & $0,93 \pm 0,03^{\mathrm{a}}$ & $0,59 \pm 0,01^{\mathrm{c}}$ & $0,67 \pm 0,02^{\mathrm{bc}}$ & $0,57 \pm 0,01^{\mathrm{c}}$ & $0,76 \pm 0,03^{\mathrm{b}}$ & $3,5-21,0$ \\
\hline Araquidico & $0,24 \pm 0,03^{\mathrm{a}}$ & $0,38 \pm 0,04^{\mathrm{a}}$ & $0,29 \pm 0,02^{\mathrm{a}}$ & $0,21 \pm 0,01^{\mathrm{a}}$ & $0,24 \pm 0,01^{\mathrm{a}}$ & $0,29 \pm 0,03^{\mathrm{a}}$ & $0,0-0,6$ \\
\hline$\alpha$-linolênico & $0,19 \pm 0,03^{b}$ & $0,21 \pm 0,02^{\mathrm{ab}}$ & $0,40 \pm 0,04^{\mathrm{a}}$ & $0,29 \pm 0,03^{\mathrm{ab}}$ & $0,21 \pm 0,01^{\mathrm{b}}$ & $0,29 \pm 0,04^{\mathrm{ab}}$ & nd \\
\hline Tricosanóico & $2,20 \pm 0,20^{\mathrm{a}}$ & $1,52 \pm 0,13^{\mathrm{a}}$ & $2,18 \pm 0,79^{\mathrm{a}}$ & $2,73 \pm 0,66^{\mathrm{a}}$ & $1,29 \pm 0,11^{\mathrm{a}}$ & $3,35 \pm 0,41^{\mathrm{a}}$ & nd \\
\hline Lignosérico & $0,62 \pm 0,06^{\mathrm{ab}}$ & $0,84 \pm 0,05^{\mathrm{a}}$ & $0,54 \pm 0,05^{\mathrm{ab}}$ & $0,82 \pm 0,04^{\mathrm{ab}}$ & $0,49 \pm 0,01^{\mathrm{b}}$ & $0,85 \pm 0,14^{\mathrm{a}}$ & $0,0-0,2$ \\
\hline Nervônico & $0,69 \pm 0,13^{\mathrm{a}}$ & $0,55 \pm 0,06^{\mathrm{a}}$ & $0,99 \pm 0,29^{\mathrm{a}}$ & $0,91 \pm 0,25^{\mathrm{a}}$ & $0,43 \pm 0,05^{\mathrm{a}}$ & $0,99 \pm 0,18^{\mathrm{a}}$ & nd \\
\hline Cervônico & $5,02 \pm 0,34^{\mathrm{ab}}$ & $3,79 \pm 0,17^{\mathrm{b}}$ & $6,29 \pm 0,57^{\mathrm{a}}$ & $6,92 \pm 0,79^{\mathrm{a}}$ & $3,26 \pm 0,16^{\mathrm{b}}$ & $7,15 \pm 0,50^{\mathrm{a}}$ & nd \\
\hline Total & 100 & 100 & 100 & 100 & 100 & 100 & 100 \\
\hline
\end{tabular}

Médias seguidas da mesma letra, na linha, são iguais entre si pelo teste de Tukey ao nível de $5 \%$ de significância. tr $=$ traços, nd $=$ não determinado. Médias obtidas de 3 repetições para cada variedade investigada.

Conforme (Tabela 3) foram identificados treze ácidos graxos nas amostras de azeites estudadas. $\mathrm{O}$ teor médio percentual dos ácidos graxos palmítico, palmitoléico, margárico, esteárico, oléico e araquídico encontrados nas cinco cultivares analisadas e no azeite de oliva extra virgem comercial, estavam de acordo com a recomendação do Codex Alimentarius (2003). Dentre as amostras analisadas, o azeite de oliva extra virgem comercial apresentou menor concentração de ácido oléico e a variedade 0025 o maior teor $(\mathrm{p}<0,05)$.

Segundo Banni et al. (1995) e Menendez et al. (2005) entre os ácidos graxos monoinsaturados, o principal é o ácido oléico, que possui, como principais efeitos, a redução do colesterol total e LDL-c, sem reduzir o HDL-c. Além disso, causa alterações na membrana das plaquetas produzindo a ação anti-trombótica (VOGNILD et al., 1998).

O teor médio de ácidos graxos monoinsaturados (palmitoléico, elaídico e oléico) foi superior as demais classes de ácidos graxos (saturados e polinsaturados). Entre os ácidos graxos saturados, o ácido palmítico foi o que apresentou maior teor, semelhante a outros estudos (PEIXOTO; SANTANA; ABRANTES, 1998; SALES et al., 2005; VOGNILD et al., 1998).

Todas as amostras avaliadas apresentaram teor médio de ácido elaídico (ácido graxo trans) acima do máximo permitido pelo Codex Alimentarius (2003), sendo que o azeite comercial e a variedade Ascolano 315 apresentaram teores mais elevados em relação aos demais $(p<0,05)$. Valores elevados também foram encontrados em amostras de azeites envasados e comercializados no Brasil analisados por Peixoto, Santana e Abrantes (1998). Estes resultados podem ser decorrentes da presença de óleos reesterificados, óleos parcialmente hidrogenados ou azeite de oliva refinado energicamente. Quanto ao teor do ácido graxo essencial linoléico, todas as amostras apresentaram concentração media inferior ao recomendado pelo Codex Alimentarius (2003). Outros estudos encontraram valores médios acima da faixa de referência (PEIXOTO; SANTANA; ABRANTES, 1998; SALES et al., 2005; VOGNILD 
et al., 1998). Entre os ácidos graxos poliinsaturados encontrados no azeite extraído das cinco variedades de oliveira, o ácido cervônico (DHA), com valores entre $3,26 \%$ a $6,92 \%$, apareceu em maior concentração.

A composição dos ácidos graxos das amostras avaliadas estava de acordo com a recomendação do Codex Aimentarius (2003) para a maioria dos ácidos graxos. Assim, apresentaram a composição característica de azeite de oliva, sendo que todas as variedades estudadas apresentaram teor médio de ácido oléico superior ao azeite extra virgem comercial $(\mathrm{p}<0,05)$.

\section{Conclusões}

A variedade de oliveira 0025 apresentou neste estudo, o menor peso médio dos frutos e maior teor de ácido oléico no azeite.

Dentre as variedades estudadas a Negroa e JB1 apresentaram teor de lipídeos e valores de acidez, índice de saponificação, iodo e peróxidos mais compatíveis com as normas da ANVISA (2005) e o Codex Alimentarius (2003), mostrando potencial para utilização na produção de azeite de oliva.

Todas as variedades cultivadas em Maria da Fé (Fazenda Experimental da EPAMIG) analisadas neste estudo apresentaram conteúdos de ácido oléico dentro do recomendado pelo Codex Alimentarius e acima do conteúdo do teor de ácido oléico do azeite comercial extra virgem analisado.

O perfil dos ácidos graxos encontrado demonstrou que todas as variedades (JB1, Negroa, Ascolano 315,0025 e 0004) estão com seus valores adequados para os ácidos graxos, quando comparados com a legislação e com o azeite extra virgem comercial utilizado.

\section{Referências}

ANVISA - Agência Nacional de Vigilância Sanitária Ministério da Saúde. Resolução $n^{\circ} 482$ de 16 de abril de 1999. Estabelece padrão de identidade e qualidade para os óleos e gorduras comestíveis, destinados à alimentação humana. Diário Oficial [da] República Federativa do Brasil, Brasília, 26 abr. 1999. Seção 1, p. 1.

ANVISA - Agência Nacional de Vigilância Sanitária Ministério da Saúde. Resolução de Diretoria Colegiada$R D C N^{o}$. 270, de 22 de Setembro de 2005. Diponível em: $<$ http://www.anvisa.gov.br.> Acesso em: 22 jun. 2008.

ASSOCIATION OF OFFICIAL ANALYTICAL CHEMISTS. Official Methods of Analysis of the Association of Official Analytical Chemists. 15. ed. Washington: AOAC, 1990. 2.v.

AUED-PIMENTEL, S.; TAKEMOTO, E.; MINAZZIRODRIGUES, R. S.; BADOLATO, E. S. G. Azeite de oliva: incidência de adulterações entre os anos de 1993 a 2000. Revista do Instituto Adolfo Lutz, São Paulo, v. 61, n. 2, p. 69-75, 2002.

BANNI, S.; DAY, B. W.; EVANS, R. W.; CORONGIO, P. F. P.; LOMBARDI, B. Detection of conjugated diene isomers of linoléico acid in liver lipids of rats fed a choline-devoid diet indicates that the diet does not cause lipoperoxidation. Journal of Nutrition Biochemistry, Worburn, v. 6, n. 5, p. 281-289, may. 1995.

BARCELOS, M. F. P. Ensaio bioquímico e sensorial de soja e guandu enlatados no estádio verde e maturação de colheita. 1998. 161 p. Tese (Doutorado em Ciências da Nutrição) - Universidade Estadual de Campinas UNICAMP, Campinas.

BENEDICO, E. C.; PÉREZ, C. A.; MARTINEZ, D. S. Aceite de oliva virgin: qué debe saber el professional de atención primaria. Centro de Salud, Temas de Hoy Zaragoza-Espanha, v.10, n. 7, set., p. 391-395. 2002.

CODEX ALIMENTARIUS COMMISSION - FAO/ WHO. Codex alimentarius, fats, oils and related oroducts. 2. ed. Roma: Secretariat of the Joint FAO/WHO Food Standards Programme, FAO, Roma, 1993. 133 p. v. 8.

Codex alimentarius, norma para los aceites de oliva y aceites de orujo de oliva Codex Stan 33-1981 (Rev. 2-2003). Disponível em: $<$ http://www.codexalimentarius. net/download/standards/88/CXS_033s.pdf.> Acesso em: 10 jul. 2008.

FOLCH, J.; LESS, M.; STANLEY, S. A simple method for the isolation and purification of total lipidis from animal tissues. Journal of biological Chemistry, Baltimore, v. 226, n. 1, p. 497-509, may. 1957. 
GOMES, J. C.; SOARES, L. F.; PEREIRA, C. A. S.; JHAM, G. N. Efeito do dessecante paraquat na qualidade da fração lipídica da soja. Ciência e Agrotecnologia, Lavras, v. 27, n. 1, p. 178-184, jan./fev. 2003.

GUILLÉN, J. H.; LÓPEZ-VILLALTA, M. C. Producción de oliva de calidad. Influencia del cultivo. Sevilha: Junta Andalucia, 1992. 101 p.

HARTMAN, L.; LAGO, R. C. Rapad preparation of fatty acid methyl esters from lipids. Laboratory Pratice, London, v. 22, n. 7, p. 475-476, 1973.

KOBORI, C. N.; JORGE, N. Caracterização dos óleos de algumas sementes de frutas como aproveitamento de resíduos industriais. Ciência e Agrotecnologia, Lavras, v. 29, n. 5, p. 1008-1014, set./out. 2005.

MATIAS, A. C.; LASTA, F. D. Calidad y estabilidad del aceite de oliva. Olivo: Estación Experimental Agropecuária Catamarca, 2001. p. 118-123.

MENENDEZ, J. A.; VELLON, L.; COLOMER, R.; LUPU, R. Oleic Acid, the main monounsaturated fatty acid of olive oil, suppresses Her-2/neu (erb B-2) expression and synergistically enhances the growth inhibitory effects of trastuzumab (Herceptin) in breast cancer cells with Her-2/neu oncogene amplification Annais of Oncology, Oxford, v. 16, n. 3, p. 359-371, mar. 2005.

MONFERRER, A.; VILLALTA, J. La fritura desde un punto de vista práctico. Alimentacion Equipos Tecnologia, Espanã, v. 12, n. 3, p. 87-91, 1993.

MORETTO, E.; FETT, R. Tecnologia de óleos e gorduras vegetais: na indústria de alimentos. São Paulo: Varela, 1998. $150 \mathrm{p}$.

OLIVEIRA, C. G. Proposta de modelagem transiente para a clarificação de óleos vegetais - experimentos cinéticos e simulação do processo industrial. 2001a. 164 p. Dissertação (Mestrado em Engenharia Química) - Universidade Federal de Santa Catarina Florianópolis, Santa Catarina

OLIVEIRA, A. F. Enraizamento de estacas semilenhosas e cultura de embriões in vitro de oliveira (olea europaea L.). 2001b. 122 p. Tese (Doutorado em Agronomia) Universidade Federal de Lavras, Lavras.

OLIVEIRA, A. F.; ANTUNES, L. E. C.; SCHUCH, M. W. Caracterização morfológica de cultivares de oliveira em coleção e considerações sobre seu cultivo no Brasil. Informe Agropecuário, Belo Horizonte, v. 27, n. 231, p. 55-62, mar./abr. 2006.
PEIXOTO, E. R. M.; SANTANA, D. M. N.;ABRANTES, $\mathrm{S}$. Avaliação dos índices de identidade e qualidade do azeite de oliva: Proposta para atualização da legislação brasileira. Boletim da Sociedade Brasileira de Ciência e Tecnologia de Alimentos, Campinas, v. 18, n. 4, p. 363470, out./dez. 1998.

PÉREZ-CAMINO, M. C.; GARCIA, J. M.; CASTELiAnO, J. M. Polar Compound concentrations in Virgin Oils from Stored Cultivar Picual Fruits. Journal of Agricultural and Food Chemistry, Washington, v. 40, n. 11, p. 2260-2262, nov. 1992.

PIO, R.; BASTOS, D. C.; BERTI, A. J.; FILHO, J. A. S.; MOURÃOFILHO, F. A. A.; ENTELMANN, F. A.; ALVES, A. S. R.; NETO, J. E. B. Enraizamento de diferentes tipos de estacas de oliveira (Olea europaea L.) utilizando ácido indolbutírico. Ciência e Agrotecnologia, Lavras, v. 29, n. 3, p. 562-567, maio/jun. 2005.

RAPOPORT, H. V. Botânica y morfologia. In: BARRANCO, D.; FERNANDEZ-ESCOBAR, R.; RALLO, L. El cultivo del olivo. 2. ed. Madri: MundiPrensa-Junta de Andalucia, 1998. 651 p.

ROBBERS, J. E.; SPEEDIE, M. K.; TYLER, V. E. Farmacognosia e farmacobiotecnologia. São Paulo: Editorial Premier, 1997. 372 p.

SALES, R. L.; COSTA, N. M. B; MONTEIRO, J. B. R.; PELUZIO, M. C. G; COELHO, S. B.; OLIVEIRA, C. G; MATTES, R. Efeitos dos óleos de amendoim, açafrão e oliva na composição corporal, metabolismo energético, perfil lipídico e ingestão alimentar de indivíduos eutróficos normolipidêmicos. Revista de Nutrição, Campinas, v. 18, n. 4, p. 499-511, jul./ago., 2005.

SANTOS, G. L. Agricultura e pecuária. SENAI-RS/ Departamento Regional, 2005. 3 p. (Resposta Técnica).

VOGNILD, E.; ELVEVOLL, E. O.; BROX, J.; OLSEN, R. L.; BARSTAD, H.; AURSAND, M.; OSTERUD, B. Effects of Dietary Marine Oils and Olive Oil on Fatty Acid Composition, Platelet Membrane Fluidity, Platelet Responses, and Serum Lipids in Healthy Humans. Lipids, Germany, v. 33, n. 4, p. 427-436, 1998.

WALKYRIA, A.. B.; LARA, H.; NAZÁRIO, G.; ALMEIDA, M. E. W.; PREGNOLATTO, W. Normas analíticas do instituto Adolfo Lutz: métodos químicos e físicos para análise de alimentos. 2. ed. São Paulo: D. D. E. Rebocho, 1976. 376 p. 
